\title{
Mediterranean Diet In Healthy Aging
}

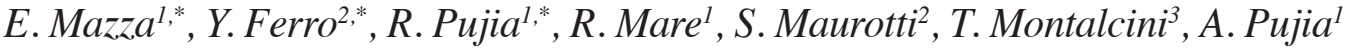

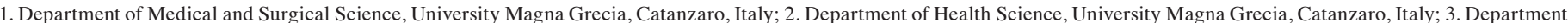
of Clinical and Experimental Medicine, University Magna Grecia, Catanzaro, Italy; * These authors contributed equally to the drafting.

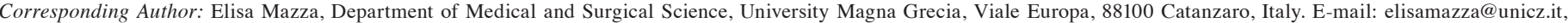
telephone numbers: +3909613697231

\begin{abstract}
The World elderly population is expected to double before 2050 . Unhealthy habits and unhealthy lifestyles are commonly associated with age-related diseases or their worsening. Modification in daily lifestyle and diet may help preventing age-related diseases onset and efficiently affecting their evolution, thus promoting the Healthy Aging process, concept recently coined to describe the disease-free aging process. This review highlights the role of nutrition science in promoting healthy aging. Since the Mediterranean Model demonstrated to be a useful style in supporting healthy aging, promotion of this correct lifestyle by health policies seems to be the best approach to achieve this target.
\end{abstract}

Key words: Healthy Aging, Mediterranean diet, nutrition, lifestyle, prevention, food intake.

\section{Introduction}

The world drastically changed over the few past centuries and people living on earth obviously adapted their lives and habits according to places and age they lived.

As a consequence of the progress and innovation in all fields, also the world population and the concepts of medicine intensely changed by time, thus spreading more and more basic concepts of prevention and increasing the people number and average age (1).

Indeed, according to the Global Health and Aging report, subjects aged 60 or older are expected to quadruple in just 4 decades, growing from an estimated 524 million in 2010 to nearly 2.1 billion in 2050 , most of which living in developing countries (2). However, the increase in the longevity of the elderly does not imply an increase in their quality of life; that constitutes a challenge to health professionals to help the growing older population not only to live longer but also healthier, better and happier (3). The current life expectancy has increased, but low-grade inflammation reduces the health expectation. Whereas advances and innovations in medicine increase life expectancy, on the other hand inflammation reduces these positive effects. The term "inflammaging" refers to the inflammation that contributes to the aging process, increasing the probability of illness (4). In fact, the advanced age also represents the main risk factor for developing chronic diseases (CD) also associated to high costs of diagnosis, treatment, and care, such as, cardiovascular disease (CVD), type 2 diabetes, cognitive decline, dementia, fragility, sarcopenia and cancer $(5,6)$. In addition, to chronic diseases of adulthood, the use of multiple medications is often mandatory in the management of the common ailments: defined «polytherapy» (7). The rapid aging of the population implies chain reactions on nations' economy, from productive sectors to medical fields. This is worsened by the COVID-19 pandemic (Coronavirus Disease 2019), today showed that the elderly is those most at risk of severe respiratory disease and higher mortality; in this last year the increased risk of developing the severe form of COVID-19 related to age has been studied ( 8 , 9).

Indeed, health expenditure for age-related pathological conditions has significant brunt on the economy of many countries, especially those highly industrialized with great health care levels $(10,11)$; this suggests the need for Health Policy makers to implement and revise the strategies to improve controlling for factors such as expenditure on health care, the existing burden of non-communicable disease and the age profile of the population (12).

Today, this trend not only resulted in a wide revolution of health concept, but it also led to the consolidation of the "healthy aging" concept, obviously referring to disease-free aging.

The World Health Organization (WHO) defined Healthy Ageing as "the process of developing and maintaining the functional ability that enables wellbeing in older age" (2). Functional ability includes a person's ability to meet their basic needs, learn, grow and make decisions, their possibility of walking freely, building or maintaining relationships, thus contributing to the society needing.

The environment in which we live obviously affects the possibility of healthy aging, because it contributes and affects people quality of life, thus playing a key role in avoiding chronic diseases. As a consequence, the best solution for Healthy Aging is not represented by diseases treatments, but through the adoption of a correct lifestyle able to prevent their onset, as well as the age-related nutritional frailty. Indeed, the healthy aging concept isn't just related to the amount of years a subject lived, but is closely linked to the quality of life, as well as to the amount of healthy active years he spent. As a consequence, correct lifestyles, and therefore also the adoption of a balanced diet, represent the basis of prevention $(13,14)$.

Nutrition and lifestyle, through the consumption of specific 
food and physical activity, help to prevent and delay the onset of diseases and helps healthy aging. Mediterranean Style (MedStyle) has shown a protective role against risk factors for age-related diseases in many studies. Mediterranean diet (MedDiet) is mainly based on the traditional foods and drinks, often homemade, characteristic of the countries surrounding the Mediterranean Sea. Over the last few decades, MedStyle has been promoted worldwide as the healthiest dietary pattern characterized by high consumption of unrefined cereals, fruit, vegetables, legumes, and olive oil; moderate consumption of dairy products and alcohol, as well as low meat consumption (15). These nutritional habits demonstrated to exert protective properties due to the high content in monounsaturated fatty acids (MUFAs) and polyphenols deriving from olive oil, polyunsaturated fatty acid (PUFAs) contained in fishes, and different antioxidants contained in fruits, legumes, vegetables and wine $(15,16)$, substances all directly linked to a reduction of the risk of the onset of chronic conditions (17) and promoting healthy aging (14). In this review, we provide an overview of the MedStyle as a promoter of healthy aging, considering the main aspects that determine the good quality of life in the elderly.

\section{Mediterranean Diet And Prevention Of Muscle Mass Reduction}

The reduction of muscle mass is a condition associated with aging, which can lead to Sarcopenia, a syndrome characterised by progressive and generalised loss of skeletal muscle mass with loss of strength. Main consequences of this pathology include decreased functional status, impaired mobility, a higher risk of falls, and in some cases also increased risk of mortality $(18,19)$. Muscle health is an integral part of healthy ageing therefore it is necessary to find a strategy to prevent an excessive reduction of muscle mass and strength related to aging.

Older individuals with overweight or mild obesity exhibiting survival advantage, usually don't manifest excessive reduction of strength and muscle mass. This represents a valuable advantage when considering that this condition is recognized as a major public health problem due to its significant clinical, economic, and social consequences (18).

Different cross-sectional studies described positive associations between MedStyle adherence and reduction in free fat mass (FFM) as well as gain in Leg explosive power (LEP) (20), this last parameter is widely used for measuring quadriceps force and velocity in muscle contraction (21). Similar concept was confirmed and strengthened also by a research protocol, who highlighted the direct link between indices of woman skeletal muscle mass and function and diet quality, the last assessed by the predefined MedDiet Score (MDS) (20). In particular, healthier dietary pattern of the MDS characterized by higher intakes in fruits, vegetables and cereals, along with lower intakes of meats, may contribute in reducing loss of skeletal muscle mass and function, especially in adult women (20). In fact, a recent meta-analysis confirmed lower incidence of fragility and functional disability in older individuals characterized by MedDiet high adherence (22). Indeed, micronutrients ingested through adherence to MedDiet, such as vitamins $\mathrm{C}$ and $\mathrm{E}$ or carotenoids, thanks to their anti-inflammatory and antioxidant properties, can guarantee preservation and conservation of skeletal muscle outcomes (23). To date, only one systematic-review has been conducted that investigated the protective role of the MedStyle in functional disability in older adults (23). This study suggests that the MedStyle may exert 'myoprotective' effects through different mechanisms of action arising from multiple dietary components, therefore, it's reasonable to think that greater adherence to MedStyle may contribute to prevent the reduction of muscle mass, also through a direct role in muscle metabolism, as in the case of magnesium and potassium minerals, typical of foods of the MedDiet (23-26). Furthermore, research has shown that alkaline diets have positive effects on lean muscle mass in healthy older individuals $(24,25,27)$. Therefore, a improve balance acid-base load of MedDiet (28) and potential reduction of diet-induced metabolic acidosis could be another beneficial element of MedStyle on the 'myoprotective' mechanism involved in muscle ageing and sarcopenia.

\section{Mediterranean Diet And Prevention Of Mineral Bone Density Reduction}

Aging process is also characterized by the physiological regression of bone tissue, regardless of gender, phenomenon that seems to have a greater outbreak in post-menopause women and can lead to osteoporosis, a systemic skeletal disease characterized by low bone mass and microarchitectural deterioration of bone tissue with a consequent increase in bone fragility and propensity to fractures. Calcium and vitamin D are main nutrients whose deficiencies are historically associated with regression of bone tissue, but different additional compounds demonstrated to be involved in bone health and well-being, such as vitamins A, B, C, E and K, minerals potassium and magnesium, silicon, and different macronutrients as proteins and fats. Indeed, these factors overall influence bone and mineral homeostasis, thus modulating long-term bone health (29).

Adherence to MedStyle has been associated with higher bone mineral density (BMD) and it has shown to prevent bone disease (30), some components of MedStyle can play a role in the prevention of osteoporosis. A recent study valued the association between the degree of MedDiet adherence and BMD in a population of Spanish premenopausal women: adherence to the MedDiet was significantly associated with BMD ( $\mathrm{p}=0.030)$ (31). Our research group demonstrated that high intake of grains, fish and olive oil was associated with a high BMD and a low number of fractures; while, legumes and wine consuming was associated with decreased odds of having fractures. Furthermore, the protective role of physical activity on bone mineral density (32), an intrinsic characteristic of the MedStyle, must also be considered. Finally, these results suggested that these specific dietary patterns in the elderly individuals as potential bone-preserving foods (33). 
The importance of these results lies in the fact that investigating individual nutrients is difficult in clinical practice and, as a consequence, consideration about their synergistic effects in dietary patterns and lifestyle is more relevant. In addition to this, the described results lay the foundations for further and in-depth clinical trials using standardized approaches, in order to evaluate the impact of different dietary style, such as the MedStyle, obviously based on solid measurements of bone quality.

\section{Mediterranean Diet And Prevention of Cardiovascular Diseases}

Cardiovascular diseases (CVD) are some of the most common Non-communicable diseases (NCDs) (34). Scientific evidences show that chronic low-grade inflammation and redox impairments constituting the molecular pathological stem of these diseases (35). Relieving the pathological pathways associated with chronic low-grade inflammation through diet and lifestyle constitute an effective strategy in the prevention of NCDs

The age-related increase in plasma cholesterol levels is generally associated to the higher incidence of coronary artery disease (CAD) in elderly $(36,37)$. Mechanisms promoting age-related hypercholesterolemia have not been completely understood, although the main factors responsible for it should be changes of the postprandial lipemia, liver sinusoidal endothelium, insulin resistance induced by free fatty acid (FFA) as well as reduced androgen expression for man (38). In last decades, different studies demonstrated that aging is associated with a gradual increase in plasma low density lipoproteins (LDL) levels in men and women, but this process seems to be more rapid in men $(37,39,40)$.

Nowadays, mechanisms exerted by MedStyle in lowering LDL-cholesterol (LDL-C) levels are not completely known, despite it has been demonstrated that phytosterols contained in different MedDiet foods contribute in reducing LDL-C by inhibition of cholesterol intestinal absorption (41), as well as by blocking proprotein convertase subtilisin/kexin-9 (PCSK9) (42). Long-term clinical trials provided strong evidences about the reduction of cardiovascular disease (CVD) in patients who adopted MedStyle, also describing detailed favourable effects on insulin sensitivity, blood pressure, lipid profiles, lipoprotein particles, oxidative stress, inflammation, and carotid atherosclerosis. In fact, unsaturated fats and polyphenols characterizing MedDiet represent the base of CVD prevention, especially in vegetable-rich diet regimes (43), finally showing lower levels of total cholesterol and lower levels of systolic blood pressure (44). In elderly individuals, a MedStyle intervention led to lower glycoxidative impairment (45) and inflammatory response $(46,47)$, compared to a diet based on consumption of saturated fatty acids.

In the past, beneficial effect exerted by MedStyle on CVD were mostly attributed to the possibility of controlling classical atherosclerosis risk factors, such as lipid concentration (37).

However, over the years, the notion that a multifactorial anti-inflammatory process is the explanation of the low CVD mortality associated with MedStyle has become increasingly widespread, due to the high content in polyphenols of MedDiet foods. In fact, overall inflammatory process plays a key role in CVD development, starting from recruitment of inflammatory cells at early stage, going through the cytokines production and up-regulation able to promote adhesion phenomena of endothelial cells, and finally considering the crucial role of inflammation process in destabilization and rupture of atheromatous plaques responsible for strokes $(37,48-50)$. These mechanisms could explain the association between reduced risk of CVD and MedStyle adherence.

\section{Mediterranean Diet And Preservation Of Sexual Capacity}

A fundamental aspect of healthy aging is the preservation of sexual capacity. Most people see their sexual life limited in old age by physiological and social factors that favour younger individuals in the reproductive stages. Nevertheless, humans are never too old to enjoy a happy and healthy sex life, despite almost everybody is surprised at the concept of staying sexually active in old age. Nonetheless, sexual activity represents a way for monitoring one's psycho-physical abilities in elderly. Indeed, it allows affirming physical functions, preventing anxiety, maintaining strong sense of identity and, obviously, gaining self-confidence (51). These aspects become particularly relevant when we consider that aging is characterized by physiological, psychosocial, behavioural and pathological changes, that can all affect sexual functioning, and it's difficult to disentangle their individual effects (52). Elderly people, as well as everybody else, may experience sexual dysfunction due to fear, boredom, fatigue, grief, low sexual desire or physical disability. In addition to this, sexuality in elderly is particularly undermine by problems such as death of a partner (51), but most of all hormonal alterations due to the increasing age, with significant decrease in term of glucocorticoids, both in men as well as in women.

According to data recently published, adherence to MedStyle improve sexual performances in the elderly (52). In fact, recent advancements about this topic demonstrated that different molecules deriving from different Mediterranean foods are efficacious in counteract the erectile dysfunction, especially those obtained from citrus, peppers, ginseng and tomatoes (52). Same authors are recently demonstrated that polyphenolic fractions deriving from Citrus Bergamia, commonly known by the name of Bergamot, a citrus fruit that grows on the Mediterranean coast of Calabria, are efficacious in counteracting erectile dysfunctions generally occurring in patients affected by type 2 diabetes (53), while another study described all positive effects due capsaicin contained in peppers and Panax ginseng in a similar category of patients (54).

As a consequence, the elderly should be provided with detailed information about benefits connected to healthy lifestyles, with lack of exceeds, daily physical activity and balanced diet regimes like the MedStyle. 


\section{Mediterranean Diet And Prevention Of Cognitive Decline}

Brain aging is characterized by the progressive and gradual addition of changes in brain structure which alter cognitive functions. These factors, overall increase the probability of age-related cognitive decline. The cognitive decline is characterized by progressive global deterioration of cognitive abilities such as memory, learning, orientation, language, comprehension and judgment. Dementia prevalence is increasing due to the aging population and symptoms related to it are severe enough to interfere with daily life (55). As all cognitive process, interaction between brain aging and nutrition is complex and it involves different pathways and districts. Current evidence suggests that the MedStyle can be employed as preventive strategies against the development of cognitive decline and dementia. A metanalysis was the first umbrella review estimating the association between the adherence to the MedStyle and 37 different health outcomes including cognitive disorders, metabolic disorders, as well as inflammatory parameters (56). The purpose of a recent metaanalysis was to explore the potential relationships of MedStyle adherence with dementia incidence rates and cognitive change over time in a traditional Mediterranean population characterized by permanent exposure to eating habits and lifestyle (57). Individuals with highest adherence to MedStyle had a $72 \%$ lower risk for development of dementia, compared to those in the lowest one ( $\mathrm{p}=0.013)$; therefore, greater adherence to MedStyle was associated with a reduced risk of cognitive decline and dementia in a traditional Mediterranean population. A systematic-review found that scheduled physical exercise of moderate-high intensity, performed 3 to 5 days a week, in people over 45 years of age with mild cognitive impairment (MCI) in their evolution to Alzheimer's disease, following a dietary pattern such as MedStyle improve overall cognitive function in subjects with MCI (58). A recent study investigated whether diet changes over 12 years were associated with cognitive function in older subjects in Southern-Italy, confirming that a traditional Mediterranean dietary pattern based on agricultural products and low alcohol consumption may help to prevent or delay age-related cognitive impairment (59). Same authors demonstrated that consuming olive oil, a major component of the Mediterranean diet, should play a beneficial effect in risk of Alzheimer's Disease thanks to its high content in phenols and other beneficial compounds (60). These results are in accordance with data previously described from a French study conducted on more than 8 thousand patients over the age of 65 . In that case, participants with moderate or intensive use of olive oil showed lower odds of cognitive deficit for verbal fluency and visual memory compared to those who never used olive oil (61). The PREDIMED-NAVARRA randomized trial valued the effect on cognition of a nutritional intervention using a Mediterranean Diet supplemented with extra-virgin olive oil (EVOO) in comparison with a low-fat control diet on 522 participants. Difference between normal diet and the Mediterranean one was considerable, especially for MedDiet supplemented with
EVOO. After over 6 years of intervention the participants who followed a Mediterranean Diet with EVOO showed significant differences in term of Mini Mental State Examination (MMSE) and Clock Darwin scores compared to control groups, thus suggesting a protective effect of olive oil against age-related cognitive impairments (62). According to these results, a randomized clinical trial sustained by our research group aimed to evaluate short-term improvements in elderly cognitive performances related to the quality of vegetable oils, rather than their quantity (63).

In detail, in the contest of a MedStyle, old patients were expected to replace vegetable oils they commonly use with lower amount of EVOO. Results we published clearly demonstrate greater cognitive function scores in subjects who consumed EVOO $(\sim 26 \mathrm{~g})$ in their MetDiet compared to those who did not replace classic vegetable oils. This led to gather that also quality of food, especially in vegetable oils, can widely affect biological parameter and improve cognitive functions, thus suggesting the greater importance of food quality compared to the quantity consumed (63) in the context of the MedStyle. The choice of different foods in elderly have a relevant impact on health. In fact, in one of our studies, we found a positive association between a high legumes pattern and the improved MMSE after an interval of 1 year, and that a dietary pattern that includes plant proteins and polyunsaturated fats is independently associated with an improvement of cognitive function after 1 year. These results would support the benefit to choose a diet including legumes and plant-based proteins in elderly for preventing cognitive decline (64). Diet is an important modifiable factor to prevent or protect against cognitive decline. Among the dietary models studied, the best evidence supports adherence to a MedStyle to reduce the risk of cognitive decline.

\section{Mediterranean Diet And Prevention Of Immune System Dysregulation}

Between organ and apparatus functions, immune response is one the most affected by age-related changes. Interactions between nutrition and immune function is essential for determining the risk of susceptibility and morbidity from infections (65-68) in the elderly. Micronutrients play a determinant role in the immune system; micronutrient deficiencies and low intakes may be likely to be detected in the elderly. This affects the risk and severity of infections and acts the clinical course and outcome of some infections (4). The most important micronutrients to support immunocompetence are vitamins $\mathrm{A}, \mathrm{D}, \mathrm{E}, \mathrm{C}, \mathrm{B} 6$ and B12, selenium and zinc, copper, folic acid and iron (69). Active vitamin $\mathrm{D}[1,25(\mathrm{OH}) 2 \mathrm{D}]$ is a steroid hormone; with high effects on human immunity. Some research suggests a relationship between the toll-like receptor (TLR) and innate immunity mediated by vitamin $\mathrm{D}$, suggesting that the different circulating levels of vitamin D may contribute to the different susceptibility to microbial infections (4). Furthermore, the elderly produce about $25 \%$ of vitamin D compared to young individuals, and hypovitaminosis $\mathrm{D}$ is endemic in this population during the 


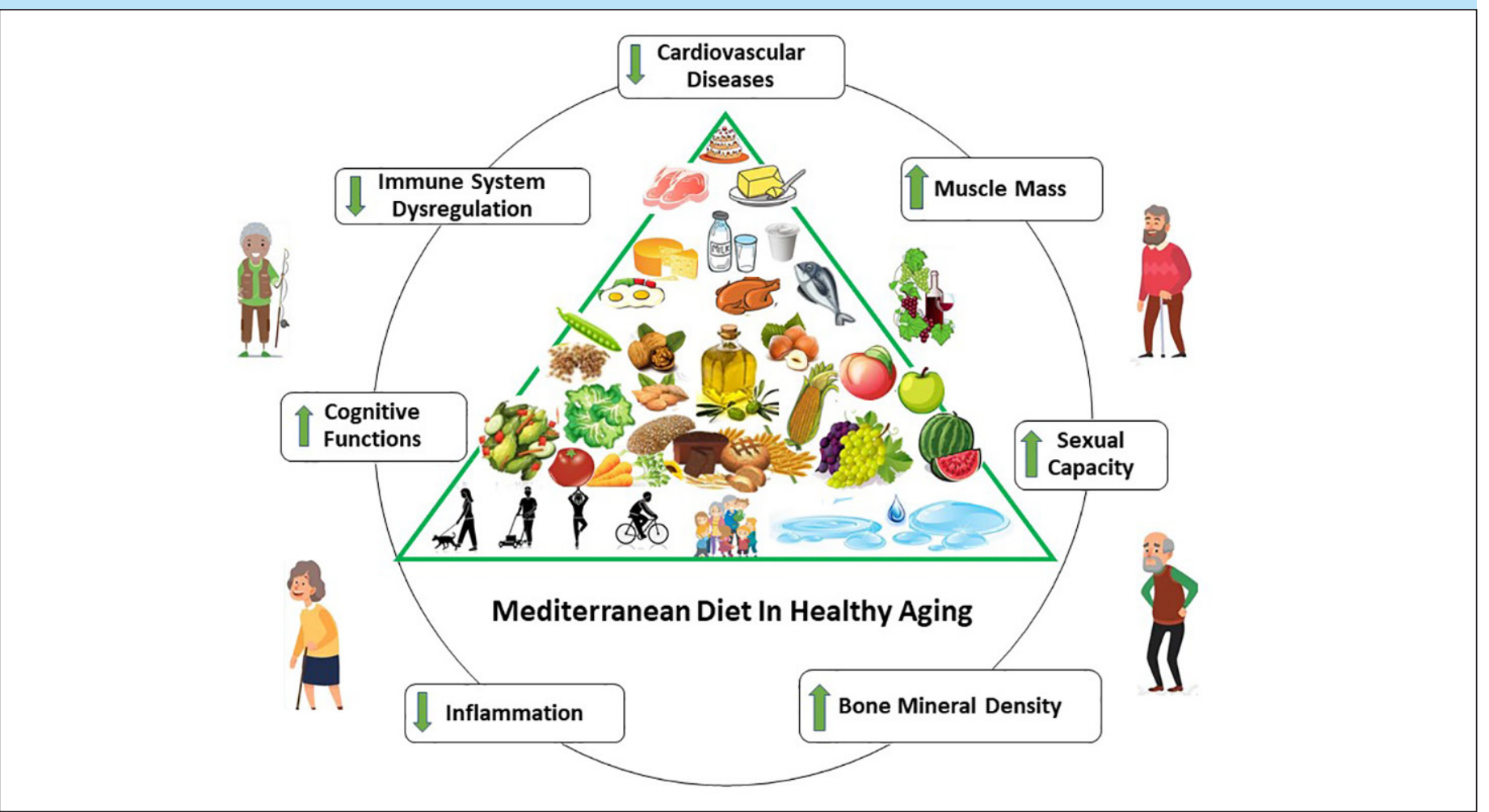

winter (70).

For these reasons, vitamin D deficiency could predispose the elderly individuals to various infections (71). Some studies have looked a correlation between vitamin D status and COVID-19 severity and mortality, to date there is insufficient evidence on the association between vitamin D levels and COVID-19 severity and mortality $(72,73)$. Therefore, randomized control trials are needed to test this hypothesis.

Vitamin E is an important fat-soluble antioxidant micronutrient richly contained in the MedStyle, widely demonstrated to be efficacious in enhancing immune functions and its supplementation, especially in elderly. This micronutrient has shown to increase immune responses, thereby increasing the resistance of elderly patients to various pathogens $(73,74)$.

Vitamin $\mathrm{C}$ promotes the synthesis of collagen supporting the integrity of epithelial barriers as well as stimulates the production and function of leukocytes, and has a role in antimicrobial activity (69).

Moreover, aging is mainly characterized by important mutation of human gastrointestinal microbiota composition, also known in medical area as gut flora or gut microbiota and which include all microorganisms, bacteria and archaea, living in human digestive tracts (75).

In detail, commensal bacteria generally contained in the colon, such as bifidobacteria, are generally destined to decrease in elderly, a simultaneous increase in proteolytic bacteria and intestinal Ag-specific secretory IgA response, which usually helps in protecting the host body through the binding of various antigens deriving from different bacteria, viruses, and fungi (65). Recent scientific evidence has shown that there is a relationship between diet, intestinal microbiome and immune system (76). It is known that diet influences the composition of the intestinal microbiota and that the microbiota, and its products, have an effect on the host $(77,78)$.

Some results suggest that the daily consumption of probiotics helps improving immune system age-related defects and reduces both incidence and severity of infections in elderly (79).

A cross-sectional study recently explored plausible associations between adherence to the MedDiet and gut microbiota profile, also evaluating gastrointestinal symptoms in adult population (80). Results described by the authors were encouraging and support the positive direct connection between MedDiet and gut microbiota profile (80). These outcomes completely agree with those described by other researchers in 2016, in which the authors reported in detail all beneficial impacts related to high adherence to MedStyle on gut microbiota $(81,82)$.

Subsequently, a project conducted in Spain, not only identified shifts and changes associated to MedDiet adherence on gut microbiota rRNA, but authors were also able to demonstrate that diet and specific dietary components affect microbiota diversity, activity and composition on adult population (83). Therefore, MedStyle, rich in micronutrients and $\omega-3$ fatty acids (EPA and DHA), could support the improvement of immune system dysregulation in the elderly by improving the immune response in elderly subjects. 


\section{Mediterranean Diet And Reduction of Inflammation: Links With Covid-19}

COVID-19 is a severe respiratory disease, caused by Coronavirus-2 (SARS-CoV-2) $(84,85)$. Recently, COVID19 has been correlated to obesity inflammation (86). In fact, metabolic disarray and inflammation are important factors in the pathogenesis of acute diseases, such as COVID-19. COVID-19 can occur at any age; however, the maximum confirmed cases and deaths have occurred among the elderly aged above 60, classified as high-risk groups and more vulnerable than other age groups (87). Several studies hypothesized that the Adherence to the MedStyle was associated with a reduction in the risk of developing the COVID-19 comorbidities. Recently in silico studies have suggested that phytochemicals typical of the MedStyle, contained principally in olive oil, could be a potential candidate to act against SARS-CoV-2 (88). The MedStyle is associated with a reduction in the inflammation, coagulation, and endothelial dysfunction markers including interleukin 6 (IL$6)$, c-reactive protein (CRP), homocysteine, fibrinogen, and E-selectin (89-91). In a Spanish ecological study, the authors observed that MedDiet adherence was negatively associated with both COVID-19 cases and related deaths (92). These results are promising; however, further studies are required to examine whether MedDiet reduces the risk of severe respiratory disease caused by COVID-19. In consideration of these observations, the MedStyle, that reduce inflammation and risk for chronic disease, could also reduce the risk of pathology and mortality by severe COVID-19.

\section{Conclusion}

The correlation between health and adherence to balanced diets is now well established at any stage of life. These aspects become even more important in the elderly, especially to achieve healthy aging.

Advancements in diet research nowadays allow identifying dietary approaches to promote healthy ageing also by food choices and combinations between foods, obviously associated with a healthy lifestyle which include daily exercise.

Adherence to the MedStyle demonstrated beneficial effects in various pathological conditions prevention, ranging from metabolic to cognitive disorders, and bringing benefits to various organs and systems, such as musculoskeletal and cardiovascular systems, thus promoting the healthy ageing process (figure 1).

In addition to this, higher adherence to the MedStyle may counteract the effect of stress-induced inflammation and has been associated with preventing effects versus different chronic diseases, including COVID-19 disease.

Indeed, MedDiet nowadays represents the best, if not the univocal, nutritional strategy for obtaining a great combination of nutrients, antioxidants and other beneficial molecules able to promote the healthy aging process.

Unfortunately, a decrease in adherence to the Me MedStyle has been recently observed all over the world, probably also due to modern lifestyles, frenetic and with high levels of stress, as well as current COVID-19 pandemic, which push people to often consume fast and unhealthy foods.

As a consequence, food education campaigns play a key role in the prevention and treatment of various pathologies, and therefore they should encourage adherence to MedStyle worldwide, especially in elderly individuals, with the aim to promote healthy aging processes.

Conflict of Interest: No potential conflict of interest relevant to this article was reported.

Funding sources: This research did not receive any specific grant from funding agencies in the public, commercial, or not-for-profit sectors

Ethical standards: This manuscript complies with current laws regarding ethical standards in Italy.

\section{References}

1. Marzetti E, Calvani R, Tosato M, Cesari M, Di Bari M, Cherubini A, et al. Sarcopenia: a1. Topp R, Fahlman M, \& Boardley D. Healthy aging: health promotion and disease prevention. Nurs Clin North Am 2004;39:411-22. https://doi.org/10.1016/j. cnur.2004.01.007.

2. Rudnicka E, Napierała P, Podfigurna A, Męczekalski B, Smolarczyk R, Grymowicz M. The World Health Organization (WHO) approach to healthy ageing. Maturitas 2020;139:6-11. doi:10.1016/j.maturitas.2020.05.018.

3. Bar-Tur L. Fostering Well-Being in the Elderly: Translating Theories on Positive Aging to Practical Approaches. Front Med (Lausanne) 2021;8:517226. doi:10.3389/ fmed.2021.517226.

4. Suardi C, Cazzaniga E, Graci S, Dongo D, Palestini P. Link between Viral Infections, Immune System, Inflammation and Diet. Int J Environ Res Public Health 2021;18:2455. doi:10.3390/ijerph18052455.

5. Beard JR, Officer AM, Cassels AK. The World Report on Ageing and Health Gerontologist 2016;56 Suppl 2:S163-S166. doi:10.1093/geront/gnw037.

6. Pelà G, Tagliaferri S, Perrino F, Righelli I, Montanari R, Longobucco Y et al Determinants of cardiac structure in frail and sarcopenic elderly adults. Exp Gerontol 2021;150:111351. doi: 10.1016/j.exger.2021.111351

7. Gujjarlamudi HB. Polytherapy and drug interactions in elderly. J Midlife Health. 2016;7:105-07. doi:10.4103/0976-7800.191021.

8. Rapp JL, Lieberman-Cribbin W, Tuminello S, Taioli E. Male Sex, Severe Obesity, Older Age, and Chronic Kidney Disease Are Associated With COVID-19 Severity and Mortality in New York City. Chest 2021;159:112-15.

9. Ng WH, Tipih T, Makoah NA, Vermeulen JG, Goedhals D, Sempa JB, et al. Comorbidities in SARS-CoV-2 Patients: a Systematic Review and Meta-Analysis. mBio 2021;12:e03647-20. doi:10.1128/mBio.03647-20.

10. Soer R, Brouwer S, Geertzen JH, van der Schans CP, Groothoff JW, Reneman MF Decline of functional capacity in healthy aging workers. Arch Phys Med Rehabil 2012;93:2326-32. https://doi.org/10.1016/j.apmr.2012.07.009.

11. Schwab K. The Human Capital Report 2013. In Geneva: World Economic Forum. 5013. [Cited 2020 Oct 27]. Available from: http://reports.weforum.org/human-capitalreport-2016/technical-notes/

12. Alhassan GN, Adedoyin FF, Bekun FV, Agabo TJ. Does life expectancy, death rate and public health expenditure matter in sustaining economic growth under COVID-19: Empirical evidence from Nigeria? [published online ahead of print, 2020 Aug 24]. J Public Aff 2020;e2302. doi:10.1002/pa.2302.

13. Chakravarty EF, Hubert HB, Krishnan E, Bruce BB, Lingala VB, Fries JF Lifestyle risk factors predict disability and death in healthy aging adults. Am J Med 2012;125:190-97. https://doi.org/10.1016/j.amjmed.2011.08.006.

14. Bonaccio M, Di Castelnuovo A, Costanzo S, Gialluisi A, Persichillo M, Cerletti C et al. Mediterranean diet and mortality in the elderly: a prospective cohort study and a meta-analysis. Br J Nutr 2018;120:841-54. doi:10.1017/S0007114518002179.

15. Bach-Faig A, Berry EM, Lairon D, Reguant J, Trichopoulou A, Dernini S, et al. Mediterranean Diet Foundation Expert Group. Mediterranean diet pyramid today Science and cultural updates. Public Health Nutr 2011;14:2274-84. https://doi. org/10.1017/S1368980011002515.

16. Grosso G, Marventano S, Yang J, Micek A, Pajak A, Scalfi L, et al. A comprehensive meta-analysis on evidence of Mediterranean diet and cardiovascular disease: Are individual components equal?. Crit Rev Food Sci Nutr 2017;57:3218-32. doi:10.1080/ 10408398.2015.1107021.

17. Schwingshackl L, Hoffmann G. Adherence to mediterranean diet and risk of cancer: a systematic review and meta-analysis of observational studies. Int J Cancer 2014;35 1884-1897. https://doi.org/10.1002/ijc.28824

18. Patel HP, Syddall HE, Jameson K, Robinson S, Denison H, Roberts HC, et al. 
Prevalence of sarcopenia in community-dwelling older people in the UK using the European Working Group on Sarcopenia in Older People [EWGSOP] definition: findings from the Hertfordshire Cohort Study [HCS]. Age Ageing 2013;42:378-84. https://doi.org/10.1093/ageing/afs197.

19. Cheng FW, Gao X, Mitchell DC, Wood C, Rolston DD, Still CD, et al. Metabolic health status and the obesity paradox in older adults. J Nutr Gerontol Geriatr 2016;35:161-76. https://doi.org/10.1080/21551197.2016.1199004.

20. Kelaiditi E, Jennings A, Steves CJ, Skinner J, Cassidy A, MacGregor AJ, et al Measurements of skeletal muscle mass and power are positively related to a Mediterranean dietary pattern in women. Osteoporos Int 2016;27:3251-60. https://doi. org/10.1007/s00198-016-3665-9.

21. Bassey EJ, Short AH. A new method for measuring power output in a single leg extension: feasibility, reliability and validity. Eur J Appl Physiol Occup Physiol 1990;60:385-90. https://doi.org/10.1007/BF00713504.

22. Silva R, Pizato N, da Mata F, Figueiredo A, Ito M, Pereira MG. Mediterranean diet and musculoskeletal-functional outcomes in community-dwelling older people: a systematic review and meta-analysis. J Nutr Health Aging 2018;22:655-63. https://doi org/10.1007/s12603-017-0993-1.

23. Granic A, Sayer AA, Robinson SM. Dietary Patterns, Skeletal Muscle Health, and Sarcopenia in Older Adults. Nutrients 2019;11:745. doi:10.3390/nu11040745.

24. Welch AA. Nutritional influences on age-related skeletal muscle loss. Proc Nutr Soc 2014;73:16-33. https://doi.org/10.1017/S0029665113003698.

25. Welch AA, MacGregor AJ, Skinner J, Spector TD, Moayyeri A, Cassidy A. A higher alkaline dietary load is associated with greater indexes of skeletal muscle mass in women. Osteoporos Int 2013;24:1899-908.

26. Guasch-Ferré M, Salas-Salvadó J, Ros E, Estruch R, Corella D, Fitó M, et al. PREDIMED Investigators The PREDIMED trial, Mediterranean diet and health outcomes: How strong is the evidence? Nutr. Metab. Cardiovasc. Dis 2017;27:624-62.

27. Dawson-Hughes B, Harris SS, Ceglia L. Alkaline diets favor lean tissue mass in older adults. Am J Clin Nutr 2008;87:662-5.

28. Chauveau P, Aparicio M, Bellizzi V, Campbell K, Hong X, Johansson L, et al. Mediterranean diet as the diet of choice for patients with chronic kidney disease. European Renal Nutrition [ERN] Working Group of the European Renal AssociationEuropean Dialysis Transplant Association [ERA-EDTA]. Nephrol Dial Transplan 2018;33:725-35.

29. Sahni S, Mangan, KM, McLean RR, Hannan MT, Kiel DP. Dietary approaches for bone health: lessons from the Framingham Osteoporosis Study. Curr Osteoporos Rep 2015;13:245-55. https://doi.org/10.1007/s11914-015-0272-1.

30. Savanelli MC, Barrea L, Macchia PE, Savastano S, Falco A, Renzullo A, et al Preliminary results demonstrating the impact of Mediterranean diet on bone health. J Transl Med 2017;15:81. https://doi.org/10.1186/s12967-017-1184-x.

31. Pérez-Rey J, Roncero-Martín R, Rico-Martín S, Rey-Sánchez P, Pedrera-Zamorano JD, Pedrera-Canal M, et al. Adherence to a Mediterranean Diet and Bone Mineral Density in Spanish Premenopausal Women. Nutrients 2019;11:555. doi:10.3390/ nu 11030555

32. Hauger AV, Holvik K, Bergland A, Ståhle A, Emaus N, Morseth B, et al. Physica capability, physical activity, and their association with femoral bone mineral density in adults aged 40 years and older: The Troms $\varnothing$ study 2015-2016. Osteoporos Int. 2021;10.1007/s00198-021-05949-9. doi:10.1007/s00198-021-05949-9.

33. Colica C, Mazza E, Ferro Y, Fava A, De Bonis D, Greco M, et al. Dietary patterns and fractures risk in the elderly. Front Endocrinol [Lausanne] 2017;8:344. https://doi org/10.3389/fendo.2017.00344

34. US Department of Agriculture; US Department of Health and Human Services Dietary Guidelines for Americans 2015-2020. 8th ed. [Internet]. Washington [DC]: USDA; US Department of Health and Human Services; 2015. [Cited 2020 Oct 27]. Available from: http://health.gov/dietaryguidelines/2015/guidelines/.

35. Casas R, Sacanella E, Estruch R. The immune protective effect of the Mediterranean diet against chronic low-grade inflammatory diseases. Endocr Metab Immune Disord Drug Targets 2014;14:245-54. doi:10.2174/1871530314666140922153350.

36. Nikkilä M, Heikkinen J. High-density lipoprotein cholesterol and longevity. Age Ageing 1990;19:119-24. https://doi.org/10.1093/ageing/19.2.119.

37. Rees K, Takeda A, Martin N, Ellis L, Wijesekara D, Vepa A, et al. Mediterranean-style diet for the primary and secondary prevention of cardiovascular disease. Cochrane Database Syst Rev 2019;3:CD009825. doi:10.1002/14651858.CD009825.pub3.

38. Liu HH, Li JJ. Aging and dyslipidemia: a review of potential mechanisms. Ageing Res Rev 2015;19:43-52. https://doi.org/10.1016/j.arr.2014.12.001.

39. Abbott RD, Garrison RJ, Wilson PW, Epstein FH, Castelli WP, et al. Joint distribution of lipoprotein cholesterol classes. The Framingham study. Arteriosclerosis 1983;3:260-72. https://doi.org/10.1161/01 .atv.3.3.260.

40. Ferrara A, Barrett-Connor E, Shan J. Total, LDL, and HDL cholesterol decrease with age in older men and women. The Rancho Bernardo Study 1984-1994. Circulation 1987;96:37-43. https://doi.org/10.1161/01.cir.96.1.37.

41. Rudkowska I, Jones PJ. Functional foods for the prevention and treatment of cardiovascular diseases: cholesterol and beyond. Expert Rev Cardiovasc Ther 2007;5:477-90. https://doi.org/10.1586/14779072.5.3.477.

42. Chan DC, Lambert G, Barrett PH, Rye KA, Ooi EM, Watts GF. Plasma proprotein convertase subtilisin/kexin type 9: a marker of LDL apolipoprotein B-100 catabolism?
Clin Chem 2009;55:2049-52. https://doi.org/10.1373/clinchem.2009.128645.

43. Martínez-González MA, Salas-Salvadó J, Estruch R, Corella D, Fitó M, Ros E, et al. Benefits of the mediterranean diet: insights from the PREDIMED Study. Prog Cardiovasc Dis 2015;58:50-60. https://doi.org/10.1016/j.pcad.2015.04.003.

44. Tzima N, Pitsavos C, Panagiotakos DB, Skoumas J, Zampelas A, Chrysohoou C, et al. Mediterranean diet and insulin sensitivity, lipid profile and blood pressure levels, in overweight and obese people; the Attica study. Lipids Health Dis 2007;6:22. https:// doi.org/10.1186/1476-511X-6-22.

45. Lopez-Moreno J, Quintana-Navarro GM, Delgado-Lista J, Garcia-Rios A, AlcalaDiaz JF, Gomez-Delgado F, et al. Mediterranean Diet Supplemented with Coenzyme Q10 Modulates the Postprandial Metabolism of Advanced Glycation End Products in Elderly Men and Women. J Gerontol A Biol Sci Med Sci 2018;73:340-46. doi:10.1093/gerona/glw214

46. Camargo A, Delgado-Lista J, Garcia-Rios A, Cruz-Teno C, Yubero-Serrano EM, Perez-Martinez P, et al. Expression of proinflammatory, proatherogenic genes is reduced by the Mediterranean diet in elderly people. Br J Nutr 2012;108:500-08 doi:10.1017/S0007114511005812.

47. Yubero-Serrano EM, Gonzalez-Guardia L, Rangel-Zuñiga O, Delgado-Lista J, Gutierrez-Mariscal FM, Perez-Martinez P, et al. Mediterranean diet supplemented with coenzyme Q10 modifies the expression of proinflammatory and endoplasmic reticulum stress-related genes in elderly men and women. J Gerontol A Biol Sci Med Sci 2012;67:3-10. doi:10.1093/gerona/glr167.

48. Estruch R. Anti-inflammatory effects of the Mediterranean diet: the experience of the PREDIMED study. Proc Nutr Soc 2010;69:333-40. https://doi.org/10.1017/ S0029665110001539.

49. Godos J, Zappalà G, Bernardini S, Giambini I, Bes-Rastrollo M, Martinez-Gonzalez M. Adherence to the Mediterranean diet is inversely associated with metabolic syndrome occurrence: a meta-analysis of observational studies. Int J Food Sci Nutr 2017;68:138-48. doi:10.1080/09637486.2016.1221900

50. Papadaki A, Nolen-Doerr E, Mantzoros CS. The Effect of the Mediterranean Diet on Metabolic Health: A Systematic Review and Meta-Analysis of Controlled Trials in Adults. Nutrients 2020;12:3342. doi:10.3390/nu12113342.

51. Kalra G, Subramanyam A, Pinto C. Sexuality: desire, activity and intimacy in the elderly. Indian J Psychiatry 2011;53:300-06. https://doi.org/10.4103/0019-5545.91902.

52. Di Francesco S, Tenaglia RL Mediterranean diet and erectile dysfunction: a current perspective. Cent European J Urol 2017;70:185-87. https://doi.org/10.5173/ ceju.2017.1356

53. Mollace V, Malara N, Gratteri S, Palma E, Zappia L, Costa N, et al. Bergamot polyphenolic fraction counteracts erectile dysfunction occurring in patients suffering from type 2 diabetes. PharmaNutrition 2016;4:S41-S46. https://doi.org/10.1016/j phanu.2015.11.006.

54. Zazdravnov A, Felix DO, Effiong UA. The role of herbal therapy [panax ginseng] in Nigeria for the treatment of atherosclerosis and erectile dysfunction in diabetic patients. 2019 available from http://repo.knmu.edu.ua/handle/123456789/23303.

55. Yankner BA, Lu T, Loerch P. The aging brain. Annu Rev Pathol 2008;3:41-66. https:// doi.org/10.1146/annurev.pathmechdis.2.010506.092044.

56. Dinu M, Pagliai G, Casini A, Sofi F. Mediterranean diet and multiple health outcomes: an umbrella review of meta-analyses of observational studies and randomised trials. Eur J Clin Nutr 2018;72:30-43. https://doi.org/10.1038/ejen.2017.58.

57. Charisis S, Ntanasi E, Yannakoulia M, Anastasiou CA, Kosmidis MH, Dardiotis E, et al. Mediterranean diet and risk for dementia and cognitive decline in a Mediterranean population. J Am Geriatr Soc 2021;69:1548-59. doi: 10.1111/jgs.17072.

58. Ballarín-Naya L, Malo S, Moreno-Franco B. Efecto de intervenciones basadas en ejercicio físico y dieta sobre la evolución de deterioro cognitivo leve a demencia en sujetos mayores de 45 años. Revisión sistemática [Effect of physical exercise and diet based interventions on the evolution of cognitive impairment to dementia in subjects older than 45 years. A systematic review.]. Rev Esp Salud Publica 2021;95:e202102032

59. Zupo R, Griseta C, Battista P, Donghia R, Guerra V, Castellana F, et al. Role of plantbased diet in late-life cognitive decline: results from the Salus in Apulia Study. Nutr Neurosci 2021;15:1-10. doi: 10.1080/1028415X.2020.1853416.

60. Angeloni C, Malaguti M, Barbalace MC, Hrelia S. bioactivity of olive oil phenols in neuroprotection. Int J Mol Sci 2017;18:2230. https://doi.org/10.3390/ijms18112230.

61. Berr C, Portet F, Carriere I, Akbaraly TN, Feart C, Gourlet V, et al. Olive oil and cognition: results from the three-city study. Dement Geriatr Cogn Disord 2009;28:357-64. https://doi.org/10.1159/000253483.

62. Martínez-Lapiscina EH, Clavero P, Toledo E, Estruch R, Salas-Salvadó J, San Julián B, et al. Mediterranean diet improves cognition: the PREDIMED-NAVARRA randomised trial. J Neurol Neurosurg Psychiatry. 2013;84:1318-25. https://doi org/10.1136/jnnp-2012-304792.

63. Mazza E, Fava A, Ferro Y, Rotundo S, Romeo S, Bosco D, et al. Effect of the replacement of dietary vegetable oils with a low dose of extravirgin olive oil in the Mediterranean Diet on cognitive functions in the elderly. J Transl Med 2018;16:10. https://doi.org/10.1186/s12967-018-1386-x.

64. Mazza E, Fava A, Ferro Y, Moraca M, Rotundo S, Colica C, et al. Impact of legumes and plant proteins consumption on cognitive performances in the elderly. J Transl Med 2017; $15: 109$ 
65. Pae M, Meydani SN, Wu D. The role of nutrition in enhancing immunity in aging. Aging Dis 2012;3:91-129.

66. Calder PC. Feeding the immune system. Proc Nutr Soc 201;72:299-309. https://doi org/10.1017/S0029665113001286.

67. Keusch GT. The history of nutrition: malnutrition, infection and immunity. J Nutr 2003;133:336S-340S. https://doi.org/10.1093/jn/133.1.336S.

68. Han SN, Meydani N. Vitamin E and infectious diseases in the aged. Proc Nutr Soc 1999;58:697-705. https://doi.org/10.1017/s0029665199000919.

69. Maggini S, Pierre A, Calder PC. Immune Function and Micronutrient Requirements Change over the Life Course. Nutrients 2018;10:1531. doi: 10.3390/nu10101531.

70. Hanley DA, Davison KS. Vitamin D insufficiency in North America. J. Nutr 2005;135:332-37.

71. Goncalves-Mendes N, Talvas J, Dualé C, Guttmann A, Corbin V, Marceau G, et al Impact of vitamin D supplementation on influenzavaccine response and immune functions in deficient elderly persons: A randomized placebo-controlled trial. Front Immunol 2019;10:65

72. Ali N. Role of vitamin D in preventing of COVID-19 infection, progression and severity. J. Infect. Public Health 2020;13:1373-80. doi: 10.1016/j.jiph.2020.06.021.

73. Jovic TH, Ali SL, Ibrahim N, Jessop ZM, Tarassoli SP, Dobbs TD, et al. Could Vitamins Help in the Fight Against COVID-19? Nutrients 2020;12:2550. doi: 10.3390/ nu12092550.

74. de Moreno de LeBlanc A, Chaves S, Carmuega E, Weill R, Antóine J, Perdigón, G. Effect of long-term continuous consumption of fermented milk containing probiotic bacteria on mucosal immunity and the activity of peritoneal macrophages Immunobiology 2008;213:97-108. https://doi.org/10.1016/j.imbio.2007.07.002 .

75. Charbonneau MR, Blanton LV, DiGiulio DB, Relman DA, Lebrilla CB, Mills DA et al A microbial perspective of human developmental biology. Nature 2016;535:48-55. doi: 10.1038/nature 18845

76. Hu J, Zhang L, Lin W, Tang W, Chan FKL, Ng SC. Probiotics, prebiotics and dietary approaches during COVID-19 pandemic. Trends Food Sci. Technol 2021;108:187-96. doi: $10.1016 /$ j.tifs.2020.12.009.

77. Tilg H, Adolph TE. Influence of the human intestinal microbiome on obesity and metabolic dysfunction. Curr Opin Pediatr 2015;27:496-501. doi:10.1097/ MOP.0000000000000234

78. Maslowski KM, Mackay CR. Diet, gut microbiota and immune responses. Na Immunol 2011;12:5-9. doi:10.1038/ni0111-5.

79. Daviglus ML, Bell CC, Berrettini W, Bowen PE, Connolly ES, Jr Cox NJ et al National Institutes of Health State-of-the-Science Conference statement: preventing alzheimer disease and cognitive decline. Ann Intern Med 2010;153:176-81. https://doi. org/10.7326/0003-4819-153-3-201008030-00260.

80. Mitsou EK, Kakali A, Antonopoulou S, Mountzouris KC, Yannakoulia M, Panagiotakos DB. Adherence to the mediterranean diet is associated with the gut microbiota pattern and gastrointestinal characteristics in an adult population. Br J Nutr
2017;117:1645-55. https://doi.org/10.1017/S0007114517001593.

81. De Filippis F, Pellegrini N, Vannini L, Jeffery IB, La Storia A, Laghi, L, et al. Highlevel adherence to a mediterranean diet beneficially impacts the gut microbiota and associated metabolome. Gut 2016;65:1812-21. https://doi.org/10.1136/ gutjnl-2015-30995757.

82. Gutiérrez-Díaz I, Fernández-Navarro T, Sánchez B, Margolles A, González S Mediterranean diet and faecal microbiota: a transversal study. Food Funct 2016;7:2347-56. https://doi.org/10.1039/c6fo00105j.

83. Garcia-Mantrana I, Selma-Royo M, Alcantara C, Collado MC. Shifts on gut microbiota associated to mediterranean diet adherence and specific dietary intakes on general adult population. Front Microbiol 2018;9:890. https://doi.org/10.3389/ fmicb. 2018.00890

84. Docea AO, Tsatsakis A, Albulescu D, Cristea O, Zlatian O, Vinceti M, et al. A new threat from an old enemy: Re-emergence of coronavirus [Review]. Int J Mol Med 2020;4:1631-43. doi:10.3892/ijmm.2020.4555.

85. Goumenou M, Sarigiannis D, Tsatsakis A, Anesti O, Docea AO, Petrakis D, et al. COVID-19 in Northern Italy: An integrative overview of factors possibly influencing the sharp increase of the outbreak [Review]. Mol Med Rep 2020;22:20-32. doi:10.3892/mmr.2020.11079.

86. Petrakis D, Margină D, Tsarouhas K, Tekos F, Stan M, Nikitovic D, et al. Obesity - a risk factor for increased COVID-19 prevalence, severity and lethality [Review]. Mol Med Rep 2020;22:9-19. doi:10.3892/mmr.2020.11127.

87. Niu S, Tian S, Lou J, Kang X, Zhang L, Lian H, et al. Clinical characteristics of older patients infected with COVID-19: A descriptive study. Arch Gerontol Geriatr 2020; 89:104058. doi: 10.1016/j.archger.2020.104058

88. Majumder D, Debnath M, Sharma KN, Shekhawat SS, Prasad GBKS, Maiti D, et al. Olive oil consumption can prevent non-communicable diseases and COVID-19: Review [published online ahead of print, 2021 Apr 12]. Curr Pharm Biotechnol 2021; 0.2174/1389201022666210412143553.doi:10.2174/1389201022666210412143553.

89. Scrivo R, Vasile M, Bartosiewicz I, Valesini G. Inflammation as "common soil" of the multifactorial diseases. Autoimmun Rev 2011;10:369-74. doi: 10.1016/j. autrev.2010.12.006.

90. Neale EP, Batterham MJ, Tapsell LC. Consumption of a healthy dietary pattern results in significant reductions in C-reactive protein levels in adults: a meta-analysis. Nutr Res 2016;36:391-401. doi:10.1016/j.nutres.2016.02.009.

91. Fernandes J, Fialho M, Santos R, Peixoto-Plácido C, Madeira T, Sousa-Santos N, et al. Is olive oil good for you? A systematic review and meta-analysis on anti-inflammatory benefits from regular dietary intake. Nutrition 2020;69:110559. doi:10.1016/j. nut.2019.110559.

92. Greene MW, Roberts AP, Frugé AD. Negative Association Between Mediterranean Diet Adherence and COVID-19 Cases and Related Deaths in Spain and 23 OECD Countries: An Ecological Study. Front Nutr 2021;8:591964. doi:10.3389/ fnut.2021.591964

How to cite this article: E. Mazza, Y. Ferro, R. Pujia, et al. Mediterranean Diet In Healthy Aging. J Nutr Health Aging. 2021;25(9):1076-1083, http://dx.doi.org/10.1007/ s12603-021-1675-6 